\title{
ChemComm
}

Cite this: Chem. Commun., 2015, 51, 5253

Received 22nd May 2014 Accepted 1st July 2014

DOI: $10.1039 / \mathrm{c} 4 \mathrm{cc} 03868 \mathrm{a}$

www.rsc.org/chemcomm

\section{Facile synthesis of a peptidic Au(I)-metalloamphiphile and its self-assembly into luminescent micelles in water}

\author{
Benedict Kemper, ${ }^{\text {ab }}$ Yana R. Hristova, ${ }^{\text {ab }}$ Sebastian Tacke, ${ }^{c}$ Linda Stegemann, ${ }^{\text {bd }}$ \\ Laura S. van Bezouwen, ${ }^{e}$ Marc C. A. Stuart, ${ }^{e}$ Jürgen Klingauf, ${ }^{C}$ Cristian A. Strassert ${ }^{\text {bd }}$ \\ and Pol Besenius*ab
}

\begin{abstract}
We report a short synthetic route for the preparation of a peptidic $\mathrm{Au}(\mathrm{I})$-metalloamphiphile which, in buffered environments of physiological ionic strength, self-assembles into luminescent micellar nanostructures of $14 \mathrm{~nm}$ in diameter.
\end{abstract}

Molecular self-assembly is a powerful bottom-up approach for the preparation of tailor-made nanomaterials, and offers distinct advantages due to reduced synthetic efforts and its reversibility which ensures error correction. ${ }^{1}$ Particularly in water, controlling supramolecular interactions has become an attractive feature to prepare nanosized architectures, for example rods, tubes, vesicles or micelles. ${ }^{2}$ The preparation of supramolecular (bio)organicinorganic hybrid materials promises to combine the best of two worlds, the predictable self-assembly encoded in the (bio)organic block and the functional properties embedded in the inorganic moiety. ${ }^{3}$ We hereby report the preparation of peptidic $\mathrm{Au}(\mathrm{I})$ metalloamphiphiles. On the one hand, we were motivated to use amphiphilic peptides because they are known to be reliable supramolecular synthons for the controlled self-assembly in water. $^{2 a_{f}, g, g}$ On the other hand, water soluble molecular Au(I)complexes have received a renewed focus in catalysis, luminescence, and medicinal chemistry. ${ }^{5}$

The self-assembly of luminescent transition metal complexes into nanostructured materials is an effective strategy for the manipulation of their photophysical properties, such as emission wavelength, excited-state lifetime and photochemical stability. ${ }^{3 a, 6}$

\footnotetext{
${ }^{a}$ Organic Chemistry Institute, Westfälische Wilhelms-Universität Münster, Corrensstrasse 40, 48149 Münster, Germany.E-mail: p.besenius@uni-muenster.de; Tel: +492518363928

${ }^{b}$ CeNTech, Heisenbergstrasse 11, 48149 Münster, Germany

${ }^{c}$ Department of Cellular Biophysics, Institute of Medical Physics and Biophysics, Westfälische Wilhelms-Universität Münster, 48149 Münster, Germany

${ }^{d}$ Physikalisches Institut, Westfälische Wilhelms-Universität Münster,

Heisenbergstrasse 11, 48149 Münster, Germany

${ }^{e}$ Department of Biophysical Chemistry, Groningen Biomolecular Sciences and Biotechnology Institute, University of Groningen, Nijenborgh 7 ,

9747 AG Groningen, The Netherlands

$\dagger$ Electronic supplementary information (ESI) available: Fig. S1-S12, synthetic procedures and full details about the instrumentation. See DOI: 10.1039/c4cc03868a
}

These parameters are crucial for developments as imaging labels in biomedical applications. ${ }^{7}$ Molecular Au(I)-complexes are exceptionally appealing due to their ability to form aurophilic interactions, some of the strongest metallophilic interactions known. ${ }^{8}$ Surprisingly however, the vast majority of luminescent molecular $\mathrm{Au}(\mathrm{I})$-complexes with short interatomic metal $\cdots$ metal distances reported is either in the solid state or in solution based on intramolecular aurophilic interactions in polynuclear complexes. ${ }^{8 c-e, 9}$ Rare exceptions are the report on metallophilic interactions in organogels by the Aida group ${ }^{10}$ and very recent work on hydrogels by the Rodriguez and Lima labs. ${ }^{11}$ Both have shown that in the gel state short $\mathrm{Au} \cdots \mathrm{Au}$ distances in the supramolecular fibres lead to luminescent properties with large Stokes shifts and long-lived emissions, which were assigned to electronic transitions from triplet-excited states. ${ }^{10,11}$

We aimed to establish a widely applicable synthetic route for equipping amphiphilic peptides with molecular Au(I)-complexes under mild reaction conditions and designed a simple strategy (Scheme 1) using the well-known oligophenylalanine supramolecular synthon as reported by Gazit, Ulijn, Xu and Adams. ${ }^{2 f, 12}$ First we prepared the propargyl amine functionalised $\mathrm{Au}(\mathrm{I})$ trisulfonated-triphenylphosphane complex $\left[\mathrm{H}_{2} \mathrm{NCH}_{2} \mathrm{C} \equiv \mathrm{CAu}^{\mathrm{I}}\right.$ (TPPTS)] 4 following a procedure reported by Laguna and coworkers. ${ }^{13}$ These types of $\mathrm{Au}(\mathrm{I})$-complexes are known to be highly stable and soluble in water ${ }^{5}$ and were prepared in three

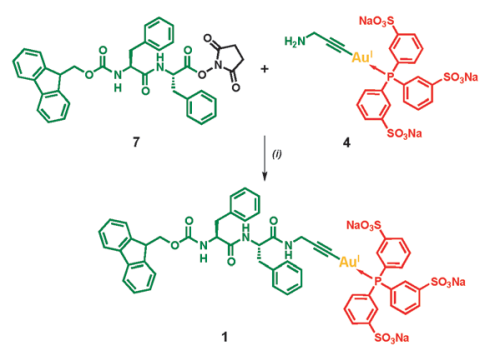

Scheme 1 Synthesis of the Fmoc-protected, dipeptidic Au(I)-metalloamphiphile 1: (i) DMF, rt; $29 \%$ yield after purification with size-exclusion chromatography. 
steps starting from hydrogen tetrachloroaurate(III) with a 88\% yield (see ESI $\dagger$ ). Complex 4 was then reacted with the $N$-hydroxysuccinimide activated fluorenylmethyloxycarbonyl diphenylalanine (Fmoc-Phe-Phe-NHS) 7 to yield the peptidic $\mathrm{Au}(\mathrm{I})$-metalloamphiphile Fmoc-Phe-Phe- $\mathrm{HNCH}_{2} \mathrm{C} \equiv \mathrm{CAu}^{\mathrm{I}}$ (TPPTS) 1 with an acceptable overall yield of $26 \%$ over four steps (Scheme 1). The final reaction was performed under neutral conditions which avoided acidic degradation of the $\mathrm{Au}(\mathrm{I})$ complex or the deprotection of the Fmoc-protecting group in a basic environment. All intermediate compounds were fully characterised by high-resolution mass spectrometry, ${ }^{1} \mathrm{H}$ and ${ }^{31} \mathrm{P}$ NMR spectroscopy.

The novel Fmoc-Phe-Phe-Au(I)-metalloamphiphile $\mathbf{1}$ is highly soluble in aqueous buffers. For comparison, we prepared another new 1,3,5-triaza-7-phosphaadamantane (TPA) functionalised peptidic $\mathrm{Au}(\mathrm{I})$-complex, Ac-Phe-Phe- $\mathrm{HNCH}_{2} \mathrm{C} \equiv \mathrm{CAu}^{\mathrm{I}}(\mathrm{TPA})$ 12, via ligand exchange of $\mathrm{ClAu}^{\mathrm{I}}$ (TPA) with Ac-Phe-Phe- $\mathrm{HNCH}_{2} \mathrm{C} \equiv \mathrm{CH}$ under basic conditions (see ESI $\dagger$ ). ${ }^{13,14}$ However this complex was not water soluble under neutral conditions and in millimolar concentrations, most likely due to the lower hydrophilicity of the phosphane, since the TPA ligand is only protonated in acidic water below $\mathrm{pH} 4.5 .{ }^{15} \mathrm{We}$ therefore focussed on investigating the luminescent properties of $\mathbf{1}$ $(66.7 \mu \mathrm{M})$ in conventional phosphate buffer $(10 \mathrm{mM}, \mathrm{pH} 7.4)$, under physiological ionic strength and at room temperature (Fig. 1A, blue curve): excitation at $\lambda_{\text {exc }}=340 \mathrm{~nm}$ leads to a broad, unstructured luminescence emission band peaking at $\lambda_{\mathrm{em}}=520 \mathrm{~nm}$. This is indicative of the formation of nanostructures incorporating short $\mathrm{Au} \cdot \mathrm{Au}$ distances: such a large Stokes shift is typically observed for Au(I)-alkynyl-phosphane complexes with short interatomic metal $\cdots$ metal distances, reported for mononuclear $\mathrm{Au}(\mathrm{I})$ complexes in the crystalline state or for polynuclear complexes in solution, which emit from long-lived triplet states. ${ }^{8 d, 9 e, f, 11,16}$
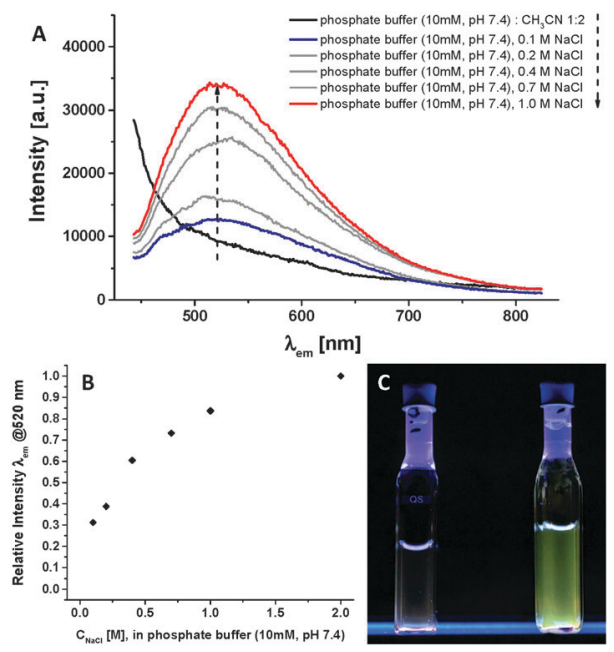

Fig. 1 (A) Emission spectra $\left(\lambda_{\text {exc }}=340 \mathrm{~nm}\right)$ of compound $1(66.7 \mu \mathrm{M})$ in $10 \mathrm{mM}$ phosphate buffer $(\mathrm{pH} 7.4)$ at $293 \mathrm{~K}$ at different ionic strengths: $0.1 \mathrm{M}$ $\mathrm{NaCl}$ (blue) $-1.0 \mathrm{M} \mathrm{NaCl}$ (red) and after addition of acetonitrile to the buffer (black) $;$ (B) relative emission intensity at $\lambda=520 \mathrm{~nm}$ as a function of the ionic strength; $(C)$ images of the luminescent $A u(I)$-metalloamphihile 1 in $10 \mathrm{mM}$ phosphate buffer $(\mathrm{pH} 7.4)\left(\lambda_{\text {exc }}=245 \mathrm{~nm}\right)$ with $0.1 \mathrm{M} \mathrm{NaCl}$ (left) and $1.0 \mathrm{M} \mathrm{NaCl}$ (right).
We obtained further evidence for the presence of nanostructures in buffered water by monitoring the luminescence after the disassembly of the aggregates. The addition of $\mathrm{CH}_{3} \mathrm{CN}$ is known to disrupt self-assembly in water, because it diminishes the hydrophobic shielding of weak intermolecular interactions. ${ }^{17}$ At the same monomer concentration of $66.7 \mu \mathrm{M}$, switching from the phosphate buffer to a $2: 1 \mathrm{CH}_{3} \mathrm{CN}$ : buffer mixture leads to the disappearance of the emission at $\lambda_{\mathrm{em}}=520 \mathrm{~nm}$, and appearance of a band at $\lambda_{\mathrm{em}}<400 \mathrm{~nm}$. The latter emission originates from the Fmoc unit in the molecularly dissolved amphiphile 1 (see also Fig. S4, ESI $\dagger$ ): in Fmoc-protected oligopeptides one generally observes quenching of the organic fluorophore $\left(\lambda_{\mathrm{em}}<400 \mathrm{~nm}\right)$ and sometimes the presence of a weak excimer band $\left(\lambda_{\mathrm{em}}=400-450 \mathrm{~nm}\right)$ in the self-assembled state. ${ }^{18}$ Hence both features, the disappearance of the lower energy band at $\lambda_{\mathrm{em}}=520 \mathrm{~nm}$ and the simultaneous appearance of the higher energy band $\left(\lambda_{\mathrm{em}}<400 \mathrm{~nm}\right)$ after disassembly, support the presence of nanostructures in buffer driven by intermolecular interactions and close contacts between the Fmoc groups as well as the $\mathrm{Au}(\mathrm{I})$ moieties.

In the self-assembled state, the emission intensity of the band at $\lambda_{\mathrm{em}}=520 \mathrm{~nm}$ is weak as one would expect for luminescent $\mathrm{Au}(\mathrm{I})$-complexes in water. ${ }^{9 f, 11}$ Furthermore, we suspected that the highly charged trisulfonated phosphane ligands on the hydrophilic head group of the metalloamphiphile 1 would hamper the self-assembly due to repulsive electrostatic interactions, and thereby weaken the luminescence. We have referred to systems like these as experiencing frustrated growth, ${ }^{2 d, 17,19}$ whereby attractive supramolecular interactions within the hydrophobic block of an amphiphilic peptide are balanced out by repulsive interactions in the hydrophilic periphery. By increasing the ionic strength from $0.1 \mathrm{M} \mathrm{NaCl}$ to $1 \mathrm{M} \mathrm{NaCl}$, we observed that the intensity of the emission band at $\lambda_{\mathrm{em}}=520 \mathrm{~nm}$ increases by a factor of three (Fig. 1A and B). The addition of $\mathrm{NaCl}$ simultaneously screens the repulsive Coulombic interactions and increases the hydrophobic effect originating from the apolar and aromatic moieties in the Fmoc-diphenylalanine block of amphiphile $\mathbf{1}$ and, consequently, stabilises the self-assembly of the highly charged monomer into nanostructures in water. ${ }^{17,19 a, d}$ The increase in the emission can then also be observed by naked eye after excitation with a $8 \mathrm{~W}$ standard laboratory fluorescent lamp (Fig. 1C). We also determined the luminescence quantum yield $\Phi=0.01$ (10 mM phosphate buffer, $\mathrm{pH} 7.4,1 \mathrm{M} \mathrm{NaCl}$, $293 \mathrm{~K}$ ). Interestingly, between $0.1 \mathrm{M}$ and $1 \mathrm{M} \mathrm{NaCl}$ the emission wavelength and the excited state lifetimes are not affected, thus indicating that rather the aggregation equilibrium but not the morphology of the aggregates or the nature of the excited state are influenced by the abovementioned Coulombic shielding (vide infra).

The long excited state lifetimes indicate that the emission at $\lambda_{\mathrm{em}}=520 \mathrm{~nm}$ is originated from a triplet state (Fig. S3, ESI $\dagger$ ). Indeed, the exponential fits of the time-resolved luminescence decay curves yield coincident values of $1.5 \mu \mathrm{s} \pm 0.1 \mu \mathrm{s}$ for both the low and high ionic strength buffers. As recently highlighted, it is often difficult to unambiguously attribute the emission of Au(I)-alkynyl-phosphane complexes to excited states with a 
defined character: the broad and structureless emission at $\lambda_{\mathrm{em}}=520 \mathrm{~nm}$ can be attributed to excited states that are approximately described as a ${ }^{3}\left[\sigma(\mathrm{Au}-\mathrm{P}) \rightarrow \pi^{*}(\mathrm{C} \equiv \mathrm{C})\right]$ metal-toligand charge-transfer excitation, or as a metal-perturbed intraligand excitation ${ }^{3} \mathrm{IL}\left[\pi \rightarrow \pi^{*}(\mathrm{C} \equiv \mathrm{C})\right]$, while $\mathrm{Au}(\mathrm{I}) \cdots \mathrm{Au}(\mathrm{I})$ interactions can contribute to the broad emission band as well. ${ }^{8 d, 9 f, 20}$ Altogether the spectroscopic investigations reveal that the aqueous self-assembly of the peptidic Au(I)-metalloamphiphile 1 into nanostructures leads to luminescent properties with large Stokes shifts and long-lived emissions, that can be assigned to triplet-excited states.

Finally, we investigated the morphology of the self-assembled nanostructures of metalloamphiphile 1 using cryogenic transmission electron microscopy (cryo-TEM). We were able to identify 10-17 nm sized spherical objects that are most probably micellar structures (Fig. S5, ESI $\dagger$ ). Micelles are known to have a swollen hydrophobic core, which unfortunately reduces contrast in cryoTEM images and makes their morphological characterisation difficult. We therefore switched to conventional TEM, using uranyl acetate as staining agent. The presence of spherical structures is clearly observed after depositing $2 \mathrm{mg} \mathrm{ml}$ solutions of 1 on carbon film coated copper grids (Fig. 2), with an averaged size of $14 \mathrm{~nm} \pm 3.5 \mathrm{~nm}$ (Fig. S10B, ESI $\dagger$ ). Assuming a length of $3.5 \mathrm{~nm}$ for the $\mathrm{Au}(\mathrm{I})$-metalloamphiphile 1, these structures are assigned to be micelles with a weakly packed peptide-based hydrophobic core that is swollen when dispersed in aqueous buffers, thus conforming cryo-TEM investigations. After comparing TEM images obtained from solutions of 1 in buffer and $0.1 \mathrm{M} \mathrm{NaCl}$, with those after adding $1 \mathrm{M} \mathrm{NaCl}$, we noticed that there is no apparent change in the diameter of the micelles (Fig. S6-S10, ESI $\dagger$ ). These results corroborate $\mathrm{NaCl}$ titrations in luminescence spectroscopy: the increased ionic strength does not lead to more densely packed micelles, since a reduced $\mathrm{Au}(\mathrm{I}) \cdots \mathrm{Au}(\mathrm{I})$ distance in supramolecular structures is known to lead to a red shift in the luminescence emission band. ${ }^{9 a, d, f}$ The spectroscopic and microscopic investigations therefore strongly suggest that by increasing the ionic strength from $0.1 \mathrm{NaCl}$ to $1 \mathrm{M} \mathrm{NaCl}$ in phosphate buffer, the formation of selfassembled micelles in solution becomes more thermodynamically favourable, without affecting the order in and size of the prepared nanostructures (vide supra). Intriguingly, when the ionic strength is kept at a minimum (10 $\mathrm{mM}$ phosphate buffer, $0 \mathrm{M} \mathrm{NaCl}$ ) we

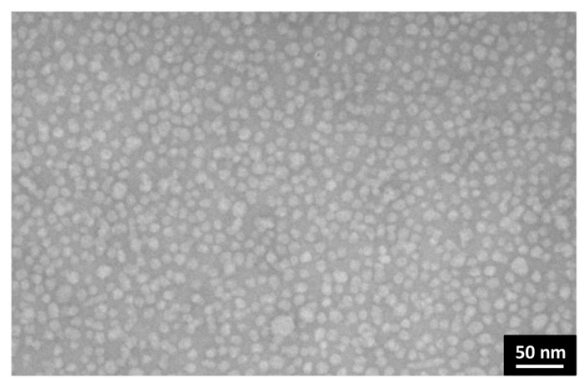

Fig. 2 TEM image of the Au(1)-metalloamphiphile 1, deposited on carbon coated grids from a $2 \mathrm{mg} \mathrm{ml}^{-1}$ solution in $10 \mathrm{mM}$ Tris buffer, $\mathrm{pH} 7.5$ and $1 \mathrm{M}$ $\mathrm{NaCl}$ (negative staining was performed with $2 \% \mathrm{w} / \mathrm{v}$ uranyl acetate). observed in cryo-TEM images that the metalloamphiphile $\mathbf{1}$ self-assembles in large sheet-like aggregates ${ }^{21}$ (Fig. S11, ESI $\dagger$ ). It is known that at very low ionic strength $(I<0.02 \mathrm{M})$ clustering of counter ions can reduce the effective charge of assemblies in solution ${ }^{22}$ which in our system is the likely cause for the formation of densely packed 2D sheets. The presence of a closely packed secondary order is furthermore supported by photoluminescence spectroscopy: excitation at $\lambda_{\text {exc }}=340 \mathrm{~nm}$ leads to a shift of the emission at $0.1 \mathrm{M} \mathrm{NaCl}$ from $\lambda_{\mathrm{em}}=520 \mathrm{~nm}$ to $550 \mathrm{~nm}$ at $0 \mathrm{M} \mathrm{NaCl}$ (Fig. S12, ESI $\dagger$ ). This red shift in the luminescence emission band suggests a reduced intermolecular $\mathrm{Au}(\mathrm{I}) \cdots \mathrm{Au}(\mathrm{I})$ distance ${ }^{9 a, d_{2} f}$ from the curved micellar structure to a planar sheet-like morphology.

We like to point out that unlike the large variety of peptide amphiphiles reported in literature, metalloamphiphile $\mathbf{1}$ does not form rod-like materials. In intermediate to high ionic strength the triple charges in the phosphane ligand as head group, compared with the small, albeit very hydrophobic FmocPhe-Phe-based peptide chain of the amphiphile, result in a high packing parameter $^{23}$ which drives the materials into highly soluble micellar structures with sizes of $14 \mathrm{~nm}$. Such small micelles are very rarely observed for peptidic supramolecular materials in water. ${ }^{2 a, f, g, 4,12}$ This is therefore a unique example where a new water soluble $\mathrm{Au}(\mathrm{I})$-metalloamphiphile self-assembles in buffered water of physiological ionic strength to form luminescent and well-defined spherical nanoparticles.

In conclusion, we present a facile synthetic route for the preparation of a new peptidic $\mathrm{Au}(\mathrm{I})$-metalloamphiphile, using a nucleophilic water soluble $\mathrm{Au}(\mathrm{I})$-complex $\mathrm{H}_{2} \mathrm{NCH}_{2} \mathrm{C} \equiv \mathrm{CAu}^{\mathrm{I}}(\mathrm{TPPTS})$, and a NHS activated peptide Fmoc-Phe-Phe-NHS. In buffered aqueous environments of medium to high ionic strength (0.1-1 M NaCl), Fmoc-Phe-Phe- $\mathrm{HNCH}_{2} \mathrm{C} \equiv \mathrm{CAu}^{\mathrm{I}}$ (TPPTS) selfassembles into luminescent micellar nanostructures with an average diameter of $14 \mathrm{~nm}$. In low ionic strength we have observed the formation of densely packed sheet-like morphologies. We assign the luminescent properties to electronic transitions from triplet-excited states due to the large Stokes and excited state life times of $1.5 \mu \mathrm{s}$, which are likely to be enhanced due to short $\mathrm{Au}(\mathrm{I}) \cdots \mathrm{Au}(\mathrm{I})$ distances in the self-assembled nanostructures. The facile synthetic strategy is fully compatible with peptide protecting group chemistry and allows for the construction of more complex peptidic nanomaterials in water, using our recently reported supramolecular synthons. By adjusting the hydrophilicity and charged character of tailor-made phosphane ligands bound to the metal complex, we aim to position functional $\mathrm{Au}(\mathrm{I})$-complexes into anisotropic nanostructures and exploit applications in bioimaging, catalysis and therapeutics.

We thank U. Malkus and A. Ricker (Institute of Medical Physics and Biophysics, Münster) for performing TEM and Dr M. Peterlechner (Institute of Material Physics, Münster) for preliminary TEM experiments. This work was supported by the DFG (SFB 858, Project B16) [B.K., Y.R.H., P.B.]; P.B. acknowledges the 'Fonds der Chemischen Industrie' for a Liebig Fellowship, the 'Nordrhein-Westfälische Akademie der Wissenschaften und der Künste' for a Fellowship via the 'Junges Kolleg' and COST Action CM1005 (Supramolecular Chemistry in Water). L.S. and C.A.S gratefully acknowledge the DFG for financial support, (SFB-TRR 61, project C07). 


\section{Notes and references}

\$ The luminescence emission spectra were recorded using a $405 \mathrm{~nm}$ filter to filter out the fluorescence from the Fmoc moieties that is generally observed in self-assembled Fmoc-dipeptides. ${ }^{18}$

1 (a) G. M. Whitesides and B. Grzybowski, Science, 2002, 295, 2418; (b) J. M. Lehn, Science, 2002, 295, 2400; (c) K. S. Chichak, S. J. Cantrill, A. R. Pease, S.-H. Chiu, G. W. V. Cave, J. L. Atwood and J. F. Stoddart, Science, 2004, 304, 1304; (d) R. J. Wojtecki, M. A. Meador and S. J. Rowan, Nat. Mater., 2010, 10, 14; $(e)$ T. Aida, E. W. Meijer and S. I. Stupp, Science, 2012, 335, 813.

2 (a) M. R. Ghadiri, J. R. Granja and L. K. Buehler, Nature, 1994, 369, 301; (b) L. Zhang and A. Eisenberg, Science, 1995, 268, 1728; (c) S. Förster and M. Antonietti, Adv. Mater., 1998, 10, 195; (d) K. J. C. van Bommel, C. van der Pol, I. Muizebelt, A. Friggeri, A. Heeres, A. Meetsma, B. L. Feringa and J. van Esch, Angew. Chem., Int. Ed., 2004, 43, 1663; (e) D. M. Vriezema, M. C. Aragonès, J. A. A. W. Elemans, J. J. L. M. Cornelissen, A. E. Rowan and R. J. M. Nolte, Chem. Rev., 2005, 105, 1445; $(f)$ R. V. Ulijn and A. M. Smith, Chem. Soc. Rev., 2008, 37, 664; $(g)$ H. Cui, M. J. Webber and S. I. Stupp, Biopolymers, 2010, 94, 1; (h) R. Chapman, M. Danial, M. L. Koh, K. A. Jolliffe and S. Perrier, Chem. Soc. Rev., 2012, 41, 6023; (i) H. Frisch, J. P. Unsleber, D. Lüdeker, M. Peterlechner, G. Brunklaus, M. Waller and P. Besenius, Angew. Chem., Int. Ed., 2013, 52, 10097.

3 (a) C. A. Strassert, C.-H. Chien, M. D. Galvez Lopez, D. Kourkoulos, D. Hertel, K. Meerholz and L. De Cola, Angew. Chem., Int. Ed., 2011, 50, 946; (b) M. J. Mayoral Munoz and G. Fernandez, Chem. Sci., 2012, 3, 1395; (c) S. Sengupta, D. Ebeling, S. Patwardhan, X. Zhang, H. von Berlepsch, C. Böttcher, V. Stepanenko, S. Uemura, C. Hentschel, H. Fuchs, F. C. Grozema, L. D. A. Siebbeles, A. R. Holzwarth, L. Chi and F. Würthner, Angew. Chem., Int. Ed., 2012, 51, 6378; (d) R. Charvet, Y. Yamamoto, T. Sasaki, J. Kim, K. Kato, M. Takata, A. Saeki, S. Seki and T. Aida, J. Am. Chem. Soc., 2012, 134, 2524; (e) M. R. Reithofer, K.-H. Chan, A. Lakshmanan, D. H. Lam, A. Mishra, B. Gopalan, M. Joshi, S. Wang and C. A. E. Hauser, Chem. Sci., 2014, 5, 625.

4 (a) J. D. Hartgerink, E. Beniash and S. I. Stupp, Science, 2001, 294, 1684; (b) L. C. Palmer, Y. S. Velichko, M. Olvera de la Cruz and S. I. Stupp, Philos. Trans. R. Soc., A, 2007, 365, 1417; (c) I. W. Hamley, Angew. Chem., Int. Ed., 2007, 46, 8128; (d) A. M. Smith, R. J. Williams, C. Tang, P. Coppo, R. F. Collins, M. L. Turner, A. Saiani and R. V. Ulijn, Adv. Mater., 2008, 20, 37; (e) X. Zhao, F. Pan, H. Xu, M. Yaseen, H. Shan, C. A. E. Hauser, S. Zhang and J. R. Lu, Chem. Soc. Rev., 2010, 39, 3480.

5 Y. R. Hristova, B. Kemper and P. Besenius, Tetrahedron, 2013, 69, 10525. 6 (a) K. Wang, M.-a. Haga, H. Monjushiro, M. Akiba and Y. Sasaki, Inorg. Chem., 2000, 39, 4022; (b) P. C. Griffiths, I. A. Fallis, T. Chuenpratoom and R. Watanesk, Adv. Colloid Interface Sci., 2006, 122, 107; (c) A. Guerrero-Martínez, Y. Vida, D. DomínguezGutiérrez, R. Q. Albuquerque and L. De Cola, Inorg. Chem., 2008, 47, 9131; (d) C. A. Strassert, M. Mauro and L. De Cola, in Advances in Inorganic Chemistry, ed. R. van Eldik and G. Stochel, Academic Press, 2011, vol. 63, p. 47; (e) M. Mauro, G. De Paoli, M. Otter, D. Donghi, G. D'Alfonso and L. De Cola, Dalton Trans., 2011, 40, 12106; $(f)$ Z. Luo, X. Yuan, Y. Yu, Q. Zhang, D. T. Leong, J. Y. Lee and J. Xie, J. Am. Chem. Soc., 2012, 134, 16662.

7 (a) V. Fernandez-Moreira, F. L. Thorp-Greenwood and M. P. Coogan, Chem. Commun., 2010, 46, 186; (b) M. Mauro, A. Aliprandi, D. Septiadi, N. S. Kehr and L. De Cola, Chem. Soc. Rev., 2014, 43, 4144.
8 (a) H. Schmidbaur, Gold Bull., 2000, 33, 3; (b) P. Pyykkö, Angew. Chem., Int. Ed., 2002, 41, 3573; (c) E. J. Fernandez, A. Laguna and J. M. Lopez-de-Luzuriaga, Dalton Trans., 2007, 1969; (d) V. W.-W. Yam and E. C.-C. Cheng, Chem. Soc. Rev., 2008, 37, 1806; (e) H. Schmidbaur and A. Schier, Chem. Soc. Rev., 2012, 41, 370.

9 (a) M. J. Irwin, J. J. Vittal and R. J. Puddephatt, Organometallics, 1997, 16, 3541; (b) J. Barberá, A. Elduque, R. Giménez, F. J. Lahoz, J. A. López, L. A. Oro and J. L. Serrano, Inorg. Chem., 1998, 37, 2960; (c) M. Enomoto, A. Kishimura and T. Aida, J. Am. Chem. Soc., 2001, 123, 5608; (d) S.-K. Yip, E. C.-C. Cheng, L.-H. Yuan, N. Zhu and V. W.-W. Yam, Angew. Chem., Int. Ed., 2004, 43, 4954; (e) R. J. Puddephatt, Chem. Soc. Rev., 2008, 37, 2012; (f) J. C. Lima and L. Rodriguez, Chem. Soc. Rev., 2011, 40, 5442.

10 A. Kishimura, T. Yamashita and T. Aida, J. Am. Chem. Soc., 2004, $127,179$.

11 (a) R. Gavara, J. Llorca, J. C. Lima and L. Rodriguez, Chem. Commun., 2013, 49, 72; (b) E. Aguilo, R. Gavara, J. C. Lima, J. Llorca and L. Rodriguez, J. Mater. Chem. C, 2013, 1, 5538.

12 (a) M. Reches and E. Gazit, Science, 2003, 300, 625; (b) V. Jayawarna, M. Ali, T. A. Jowitt, A. F. Miller, A. Saiani, J. E. Gough and R. V. Ulijn, Adv. Mater., 2006, 18, 611; (c) Z. Yang, G. Liang, L. Wang and B. Xu, J. Am. Chem. Soc., 2006, 128, 3038; (d) D. J. Adams, M. F. Butler, W. J. Frith, M. Kirkland, L. Mullen and P. Sanderson, Soft Matter, 2009, 5, 1856.

13 S. Sanz, L. A. Jones, F. Mohr and M. Laguna, Organometallics, 2007, 26, 952.

14 E. Vergara, E. Cerrada, A. Casini, O. Zava, M. Laguna and P. J. Dyson, Organometallics, 2010, 29, 2596.

15 Z. Assefa, B. G. McBurnett, R. J. Staples, J. P. Fackler Jr., B. Assmann, K. Angermaier and H. Schmidbaur, Inorg. Chem., 1995, 34, 75.

16 N. J. Long and C. K. Williams, Angew. Chem., Int. Ed., 2003, 42, 2586.

17 (a) P. Besenius, G. Portale, P. H. H. Bomans, H. M. Janssen, A. R. A. Palmans and E. W. Meijer, Proc. Natl. Acad. Sci. U. S. A., 2010, 107, 17888; (b) M. von Gröning, I. de Feijter, M. C. A. Stuart, I. K. Voets and P. Besenius, J. Mater. Chem. B, 2013, 1, 2008.

18 (a) S. Fleming, S. Debnath, P. W. J. M. Frederix, N. T. Hunt and R. V. Ulijn, Biomacromolecules, 2014, 15, 1171-1184; (b) Y. M. AbulHaija, S. Roy, P. W. J. M. Frederix, N. Javid, V. Jayawarna and R. V. Ulijn, Small, 2014, 10, 973.

19 (a) H. Dong, S. E. Paramonov, L. Aulisa, E. L. Bakota and J. D. Hartgerink, J. Am. Chem. Soc., 2007, 129, 12468; (b) F. Versluis, H. R. Marsden and A. Kros, Chem. Soc. Rev., 2010, 39, 3434; (c) A. Ghosh, M. Haverick, K. Stump, X. Yang, M. F. Tweedle and J. E. Goldberger, J. Am. Chem. Soc., 2012, 134, 3647; (d) C. Schaefer, I. K. Voets, A. R. A. Palmans, E. W. Meijer, P. van der Schoot and P. Besenius, ACS Macro Lett., 2012, 1, 830.

20 (a) D. Li, X. Hong, C.-M. Che, W.-C. Lo and S.-M. Peng, J. Chem. Soc., Dalton Trans., 1993, 2929; (b) V. W.-W. Yam, S. W.-K. Choi and K.-K. Cheung, Organometallics, 1996, 15, 1734; (c) V. W.-W. Yam, K.-L. Cheung, S.-K. Yip and K.-K. Cheung, J. Organomet. Chem., 2003, 681, 196; (d) M. Ferrer, A. Gutiérrez, L. Rodríguez, O. Rossell, J. C. Lima, M. Font-Bardia and X. Solans, Eur. J. Inorg. Chem., 2008, 2899; (e) X. He, E. C.-C. Cheng, N. Zhu and V. W.-W. Yam, Chem. Commun., 2009, 4016.

21 J. T. van Herpt, M. C. A. Stuart, W. R. Browne and B. L. Feringa, Chem. - Eur. J., 2014, 20, 3077.

22 (a) T. Odijk, Biophys. Chem., 1991, 41, 23; (b) P. van der Schoot, Langmuir, 1997, 13, 4926.

23 J. N. Israelachvili, D. J. Mitchell and B. W. Ninha, J. Chem. Soc., Faraday Trans. 2, 1976, 72, 1525. 